The Open Civil Engineering Journal
CrossMark
Content list available at: www.benthamopen.com/TOCIEJ/
DOI: $10.2174 / 1874149501711011106$

RESEARCH ARTICLE

\title{
Seismic Vulnerability and Damage Speedy Estimation of an Urban Sector within the Municipality of San Potito Sannitico (Caserta, Italy)
}

\author{
Antonio Formisano ${ }^{1, *}$, Nicola Chieffo ${ }^{2}$ and Marius Mosoarca ${ }^{2}$ \\ ${ }^{I}$ Department of Structures for Engineering and Architecture, University of Naples Federico II, Piazzale Tecchio 80, \\ Naples, Italy \\ ${ }^{2}$ Politehnica University of Timisoara, Str. Traian Lalescu, Timisoara, Romania
}

Received: November 20, 2016

Revised: January 14, 2017

Accepted: March 13, 2017

\begin{abstract}
:
Introduction:

The preservation of masonry buildings typical of Italian historical centres represents a very pressing dilemma founded on recovery need of the urban fabric original character.
\end{abstract}

\section{Methods:}

In the paper, based on a speedy methodology developed by some of the authors on building aggregates, the seismic vulnerability quick estimation of some masonry compounds in the heart of the town of San Potito Sannitico (Caserta, Italy) is presented and compared to the results achieved from applying the basic literature method for isolated constructions.

\section{Results and Conclusion:}

Finally, the damage scenario of inspected buildings has been shown by highlighting clearly the influence of different positions of structural units on the damages that masonry aggregates should suffer under different grade earthquakes, leading to individuate the most vulnerable buildings.

Keywords: Masonry aggregates, Seismic risk, Seismic vulnerability, Quick methods, Damage analysis, Urban sector.

\section{STATE-OF-THE ART}

The Italian historical centres are made up of masonry building aggregates characterised from an articulated genesis occurred during the centuries due to multiple factors, such as construction sequence, change of materials and variation of needs, as well as the relationship between the aggregation of building materials and both the morphological evolution of the urban system and the major events that have influenced the typological aspects of historical buildings. Therefore, the historical centres describe the image of a city, representing the historical memory of the ancient art of building.

In the framework of a comprehensive study on the seismic risk of historical centres, large attention should be paid to the assessment of the vulnerability of constructions $(\mathrm{V})$, of the seismic hazard $(\mathrm{H})$ and of the exposure $(\mathrm{E})$, the latter representing the number of assets (economic damages, damaged constructions and loss of human lives) exposed to risk.

About vulnerability (V), it is of fundamental importance for the historical centres preservation, the most comprehensive knowledge of the built-up that should be based on survey operations and historical and experimental research studies.

Generally, masonry buildings were built on the experience gained over the centuries for the construction of similar

\footnotetext{
* Address correspondence to this author at the Department of Structures for Engineering and Architecture, University of Naples Piazzale Tecchio 80, Naples, Italy; Tel: +00390817682438; Fax:+00390815934792; E-mail: antoform@unina.it
} 
structures; nevertheless, ordinary buildings located in the historical centres are often made of different quality masonries and constructive details that can highlight deficiencies with respect to safety conditions against seismic actions. In fact, the lack of appropriate connections among walls and between floors and walls led, in case of earthquake, to the modification of the pressure curve induced by the vertical loads, so resulting in the formation of cracks which, in severe cases, can produce the partial or total collapse of buildings.

Significant studies [1] have focused on the identification of typical seismic vulnerability of historic masonry buildings based on the observation of damages deriving from past earthquakes which affected the historical centres.

During this analysis process, particular attention should be paid to the building aggregates, since when different structural units are placed in continuity with each other to the possible interactions resulting from their structural contiguity, which could be based on either shared walls or walls simply placed alongside one another, should be taken into account. Moreover, the presence of both staggered floors and buildings with different heights represents further interaction factors among structural units to be considered.

Unfortunately, several past studies concerned the behaviour of isolated structural units rather than the entire aggregates one. A correct analysis procedure should be instead based on the evaluation of the seismic behaviour of whole building compounds which, from the structural point of view, are made of constructions arranged according to complex plan and in elevation patterns, strongly interacting with each other when subjected to seismic actions $[2,3]$.

It is, therefore, fundamental to determine preliminarily the aggregate Structural Units (S.U.), that is individual behavioural units of the masonry compound to be inspected [4]. Moreover, in order to examine in detail the seismic behaviour of buildings in the historical centres, the entire aggregate should be examined taking into account both the unified structural behaviour of constitutive units against static and dynamic actions and the spatial connections among adjacent buildings. The S.U. must be identified on the basis of the building system shape which they belong to and they can be composed of one or more housing units. In any case, S.U. must have continuity in elevation for the transmission of vertical loads and they must be separated from adjacent buildings made, for example, of different structural types or erected in different ages with different materials. Among the structural interactions with the adjacent buildings, one must consider the vertical and horizontal actions deriving from staggered floors or from the adjacent walls of near S.U. Furthermore, the counteracted pressures generated by vaults belonging to neighbouring S.U. on shared walls and the pressures coming from contrast arches or tie rods anchored on other buildings which, in case of earthquakes, can induce the failure of walls should be considered. In particular, after the seismic event, the masonry buildings, according to their characteristics, can undergo local or global collapses. Two different types of failure mechanisms, namely first-order mechanisms (overturning, vertical arch effect, horizontal arch effect and corner overturning as the main mechanisms) and second order ones (diagonal shear, sliding shear and compression-bending), can affect masonry walls. The Italian Technical Code [2] and the related Ministerial Circular [5] indicate that the seismic safety evaluation of existing masonry buildings (Section C8.7.1.1) should be performed with reference to both the overall seismic behaviour and the local collapse mechanisms.

The mechanisms interested either individual masonry walls or larger portions of the building and they are promoted by the absence or ineffectiveness of the connections among walls and between walls and horizontal structures. The presence of crack patterns and damage produced by past earthquakes provide an effective indication for a correct prediction of incipient collapse mechanisms. The individuation of significant collapses for buildings is so accomplished primarily through the search for disconnections, already detected or appearing in masonry structures due to seismic actions, which identify macro elements, considered as more or less extensive portions of walls that, when made of adequate quality masonry, behave monolithically and are susceptible to instability. As a consequence, it is clear that the examination of the seismic behaviour and possible collapse conditions of an existing masonry building cannot be done without a careful assessment of the above structural features. Therefore, the building geometrical configuration, the masonry type and quality, the effectiveness of connections among both vertical resistant elements and between walls and horizontal structures, the actions exerted on the structural elements, recognising unfavourable equilibrium conditions (presence of unopposed pressures), the possible degradation state, the crack pattern and the possible interaction with both adjacent structures and ground should be taken into account.

In the past decades, different vulnerability assessment methods for buildings grouped in compounds, distinguished as large scale analyses [6 - 12] and refined ones [13 - 19] were developed.

Instead, the seismic hazard $(\mathrm{H})$ is dependent on both the event physical characteristics and the geological characteristics of the area in which the event occurs: the higher is the frequency and intensity of events characterising 
geographical area, the greater is the hazard. In view of seismic risk mitigation, these analyses should be performed on whole regional or urban areas and, therefore, on a large number of buildings and infrastructures. An effective strategy for mitigation of seismic risk depends on either the adequate assessment of seismic hazard or the determination of the ground motion properties associated with future earthquakes, in terms of displacement, velocity or acceleration. In fact, the seismic hazard is related to a natural phenomenon typically aleatory in terms of occurrence probability and frequency, which can affect areas with different geological characteristics [20]. The techniques used for the estimation of the hazard are probabilistic methods and deterministic ones. The probabilistic methods for seismic hazard assessment are based on the information delivered by the seismic history of a site, they providing the probability rate that the soil motion exceeds a certain limit within a predetermined time interval. In this sense, therefore, the seismic hazard $(\mathrm{H})$ represents the probability measure $(\mathrm{P})$ of the severity degree of earthquakes, expressed for example by the intensity parameter (I), which may occur at a given site during a specified time interval. Contrary, the deterministic approaches for seismic hazard assessment are based on ground motion modelling by creating synthetic seismograms, considering only the maximum events listed in the historic catalogue, which were the most dangerous. Basically, with this method, the area is discretised into a grid composed of the so-called cells. At the centre of each cell is given a type of seismic source, determined by considering the maximum magnitude observed in the epicentre area of that cell considered.

Based on these premises, many studies for the risk assessment of historic urban area were developed [21 - 27].

In the current paper the vulnerability assessment of a large part of the historical centre of San Potito Sannitico, placed in the district of Caserta, is presented as initial stage of a more wide study having the final goal to evaluate the seismic risk of the whole urban built-up investigated.

\section{THE VULNERABILITY FORM}

Aiming at implementing a speedy seismic evaluation procedure for masonry aggregates, the starting point has been represented by the Benedetti e Petrini's methodology [28], widely used in the past as a quick technique based on collecting into an appropriate form some information on single buildings for investigating their vulnerability under earthquake. This vulnerability assessment form, whose basic ten parameters used to recognise the main structural system and its fundamental seismic deficiencies are reported in Table $\mathbf{1}$ with white background, has been adopted with some small adjustments by the Italian National Group Against Earthquakes as first screening tool for vulnerability assessment of masonry and r.c. buildings belonging to historical centres affected by seismic actions.

In order to consider the structural interaction among adjacent buildings, not considered in the cited method, a new form has been ideated. The new survey form appropriately conceived for masonry building aggregates is resulted from adding to the basic ten parameters of the original form new five parameters taking into account interaction effects among aggregate structural units under earthquakes $[8,29]$. The new form is still depicted in Table $\mathbf{1}$, where new five parameters appear on a grey background.

These factors, in part derived from previous studies found in literature [3], are:

1. In elevation interaction;

2. Plan interaction;

3. Number of staggered floors;

4. Structural or typological heterogeneity among adjacent structural units;

5. Percentage difference of opening areas among adjacent facades.

The effect of the above parameters on the behaviour of masonry building compounds has been investigated through macro-element analysis carried out with the TREMURI software [30] on a case study of a historical aggregate within the municipality of Sessa Aurunca in the district of Caserta (Italy) [31].

First of all, the in elevation interaction among adjacent buildings takes into account the different height of adjacent buildings (Fig. 1). Buildings placed between constructions of the same height or higher are the less vulnerable cases because the external constructions provide confinement actions on the building walls considered when they deform in their plane under seismic actions. Contrary, the most dangerous cases are when the building is within two shorter constructions (one and two floors). In fact, in these cases, since the constraining action of adjacent buildings is partially provided only, the central building is free to deform laterally at last levels. In this case, out-of-plane collapse of top storey masonry walls impact on the last floors of adjacent buildings, so to eventually lead towards their failure. 
a)

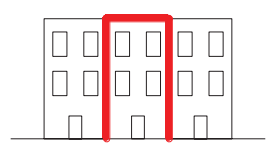

b)

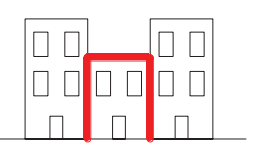

a)

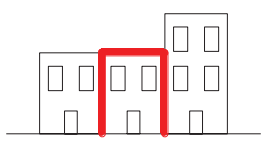

c)

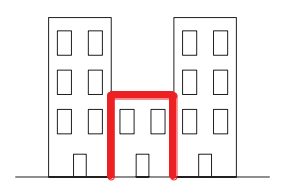

d)

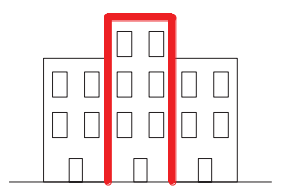

e)

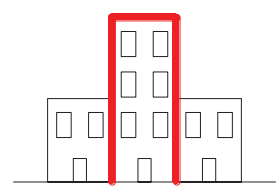

f)

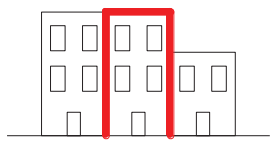

f)

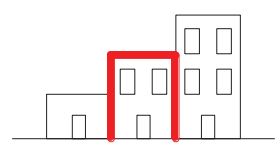

Fig. (1). Different conditions regarding the in elevation interaction among buildings in aggregates.

Later on, the planimetric interaction parameter among structural units has been considered. In particular, it is possible to distinguish different positions and, therefore, different behaviour of the buildings, depending on their position in the aggregate. Four different positions of the building, namely isolated (Fig. 2a), within other buildings (Fig. 2b), in the aggregate corner (Fig. 2c) and in a leading position of the aggregate (Fig. 2d), can be distinguished.

The analysis results deriving from macro-element model have shown that the lower vulnerability index is attained when building is within two edifices.

Table 1. The new vulnerability assessment form for building aggregates.

\begin{tabular}{|l|c|c|c|c|c|}
\hline Parameter & \multicolumn{2}{|c|}{ Class score (s) } & \multirow{2}{*}{ Weight $(w)$} \\
\hline 1. Organization of vertical structures & A & B & C & D & \\
\hline 2. Nature of vertical structures & 0 & 5 & 20 & 45 & 1 \\
\hline 3. Location of the building and type of foundation & 0 & 5 & 25 & 45 & 0.25 \\
\hline 4. Distribution of plan resisting elements & 0 & 5 & 25 & 45 & 0.75 \\
\hline 5. In-plane regularity & 0 & 5 & 25 & 45 & 1.5 \\
\hline 6. Vertical regularity & 0 & 5 & 25 & 45 & 0.5 \\
\hline 7. Type of floor & 0 & 5 & 25 & 45 & $0.5 \div 1$ \\
\hline 8. Roofing & 0 & 5 & 15 & 45 & $0.75 \div 1$ \\
\hline 9. Details & 0 & 15 & 25 & 45 & 0.75 \\
\hline 10. Physical conditions & 0 & 0 & 25 & 45 & 0.25 \\
\hline 11. Presence of adjacent buildings with different height & 0 & 5 & 25 & 45 & 1 \\
\hline 12. Position of the building in the aggregate & -20 & 0 & 15 & 45 & 1 \\
\hline 13. Number of staggered floors & -45 & -25 & -15 & 0 & 1.5 \\
\hline 14. Structural or typological heterogeneity among adjacent structural units & 0 & 15 & 25 & 45 & 0.5 \\
\hline 15. Percentage difference of opening areas among adjacent facades & -15 & -10 & 0 & 45 & 1.2 \\
\hline
\end{tabular}

The presence of staggered floors has been contemplated accounting for the effect of pounding caused by floors placed at different heights in adjacent buildings. In order to calibrate the parameter related to the influence of staggered floors among aggregated buildings, the following five conditions have been modelled:

a. total absence of staggered floors (Fig. 3a);

b. presence of one staggered floor (Fig. 3b);

c. presence of two staggered floors at the same level (Fig. 3c);

d. presence of two staggered floors at different levels (Fig. 3d);

e. presence of four staggered floors (Fig. 3e). 
a)

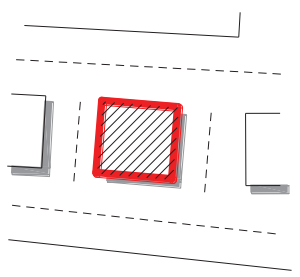

c)

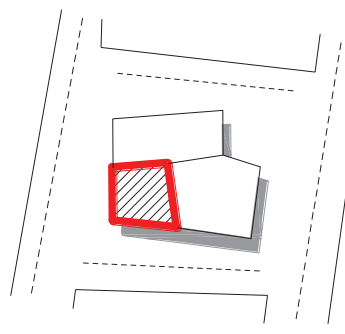

Fig. (2). Possible positions of the building into the aggregate.

a)



c)

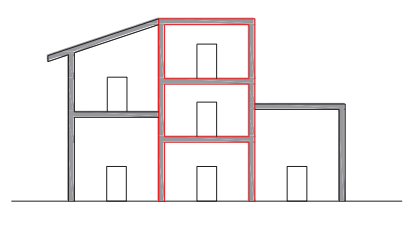

b)

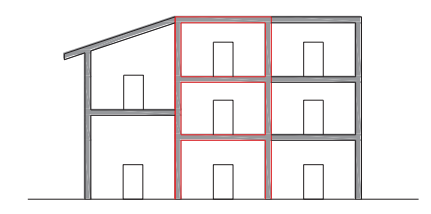

d)

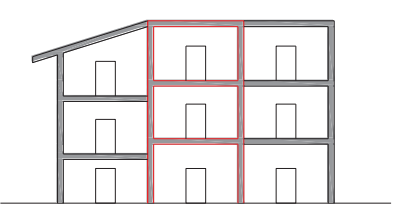

e)

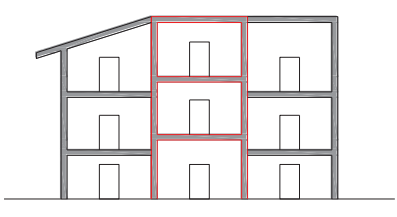

Fig. (3). Possible positions of staggered floors in the aggregate.

This pushing action of floors can cause either damage or out-of-plane collapse of walls. Nevertheless, considering that the height difference among floors is not very considerable, the pounding effect does not produce very important negative consequences on the in-plane behaviour of masonry walls. However, even if in a negligible way, as observed from numerical analyses, the vulnerability index augments as the number of staggered floors increases.

Later on, the parameter regarding either structural or typological heterogeneity among adjacent structural units has been examined. In order to standardise this parameter, the following four possible conditions have been taken into account:

a. aggregate buildings are homogeneous from typological and structural viewpoints (Fig. 4a); 
b. the building is adjacent to buildings made of the same material but erected with a construction technique worse than the examined one (Fig. 4b);

c. the building is close to buildings made of the same material but erected with a construction technique better than the examined one (Fig. 4c);

d. the building has a structural typology very different from that of the adjacent one (Fig. $\mathbf{4 d}$ ).

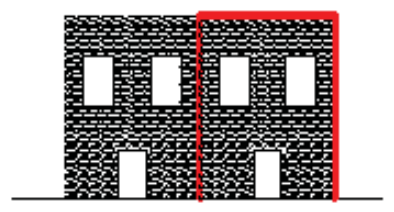

a)

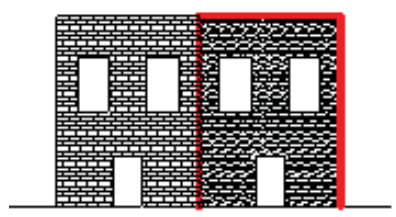

c)

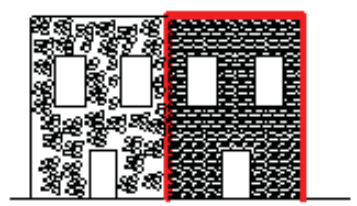

b)

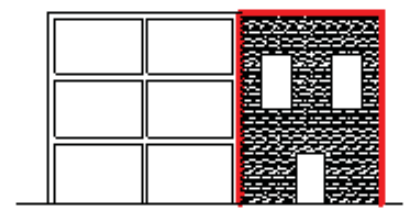

d)

Fig. (4). Structural or typological heterogeneity among adjacent structural units: building adjacent to a same masonry building (a), a low-quality masonry building (b), a high-quality masonry building (c) and a reinforced concrete building (d).

Recent studies [29] have enabled to understand that the worst condition for a masonry building placed in aggregate is when it is adjacent to a reinforced concrete building and that the best condition comes from a building next to a masonry construction with worst features.

a)

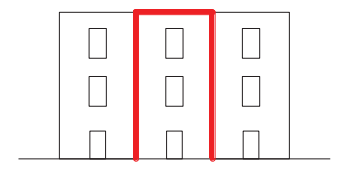

b)

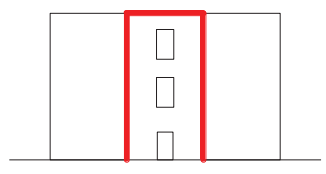

c)

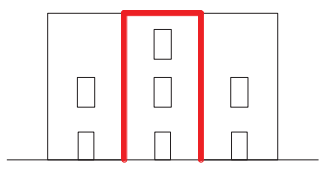

d)

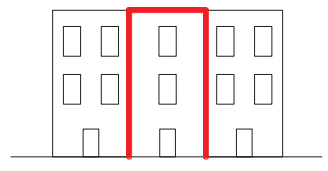

e)

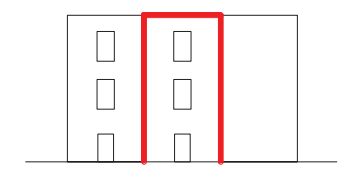

Fig. (5). Different percentages of opening areas among adjacent facades.

Finally, the parameter accounting for the percentage difference of opening areas among adjacent structural units has been assessed by considering the following five cases:
a. no difference among adjacent facades (Fig. 5a);
b. difference more than $50 \%$ (Fig. 5 b);
c. difference more than $25 \%$ (both sides) (Fig. 5c);
d. difference less than $25 \%$ (Fig. 5d);
e. difference more than $25 \%$ (from one side only) (Fig. 5e).

The percentage of openings influences the seismic response of the façade. In particular, a large percentage 
difference of openings between two adjacent facades would influence the distributions of horizontal actions between them. Moreover, it is apparent that the worst condition is achieved when the opening area of the study unit is less than $25 \%$ of the adjacent structural units one.

\section{THE HISTORICAL CENTRE OF SAN POTITO SANNITICO}

San Potito Sannitico is an Italian town with 2,011 residents within the province of Caserta in the Campania region of Italy. It extends on about $22 \mathrm{~km}^{2}$ and belongs to the Matese Regional Park (Fig. 6).
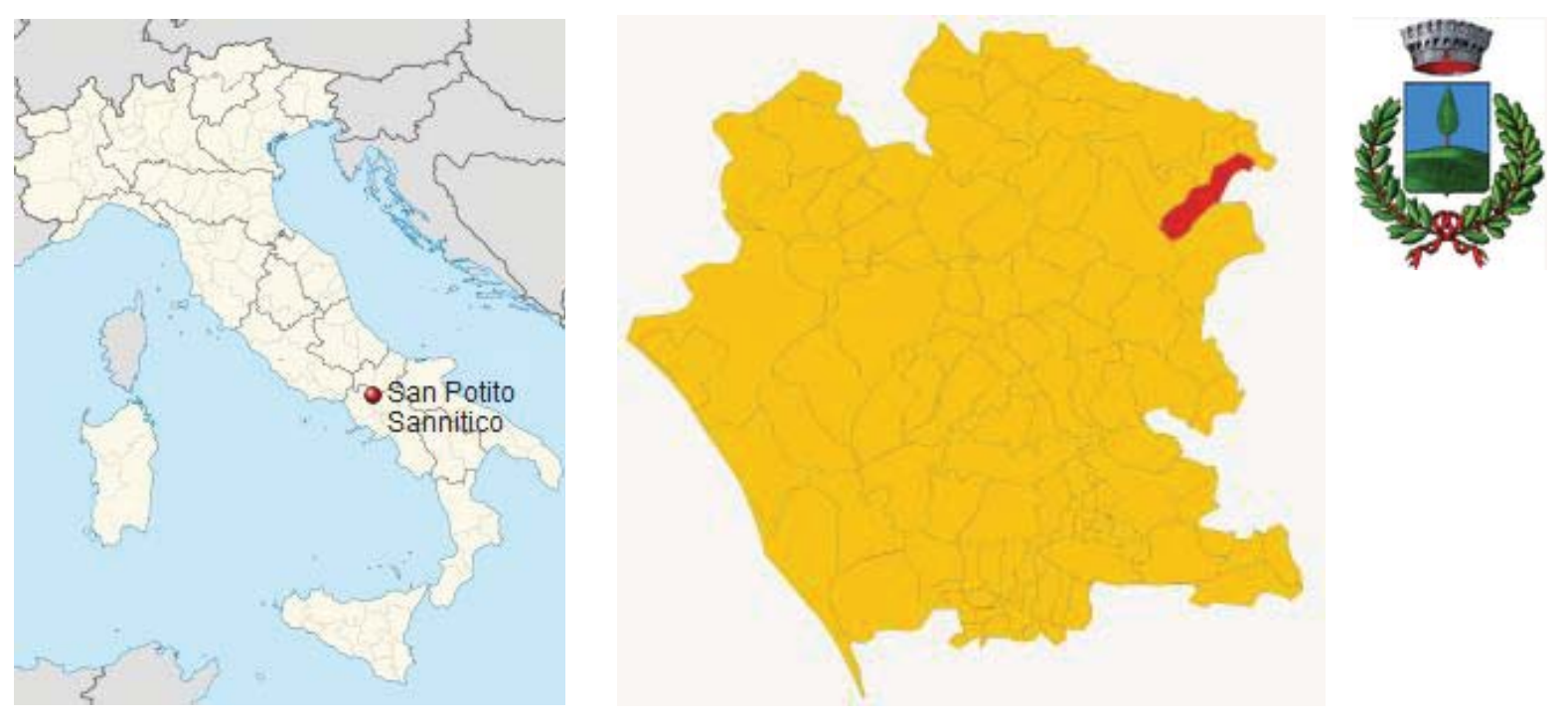

Fig. (6). Geographical localization of the city of San Potito Sannitico.

The town is placed in the Sannio-Matese territory forming part of the Apennines and it is classified as a high seismicity zone. This part of Apennines, that extends from Abruzzo region to the Basilicata one, is in fact one of the most active seismic areas of Italy. The whole Campania region has been divided into seismic zones with different intensity depending on the peak ground accelerations detected by the geographical coordinates of the project area, which can be modified according to the reference life of structures considered. For a more quick assessment of the seismic hazard of the Campania region, reference to the old seismic classification provided in 2002 can be made. Following this seismic micro-zoning, a base hazard value, expressed in terms of maximum acceleration on rigid ground, is assigned. The whole territory is divided into Zone 1 (red zone), a high seismic intensity area where 129 municipalities fall, Zone 2 (yellow zone), a medium seismicity area where 360 municipalities are located, and Zone 3 (blue zone), a low seismicity area which includes 62 municipalities (Fig. 7).

San Potito taken its name from the homonym saint of the $2^{\text {nd }}$ Century. The territory was inhabited since antiquity, as evidenced by some archaeological finds. In the fifteenth century it was called Casale Sancti Potiti and depended administratively from the municipality of Piedimonte Matese. In 1615 the town obtained a first and partial administrative autonomy that led to the establishment of an independent municipality in 1749. Since 1862 it is called San Potito Sannitico. During World War II, it escaped physical damage from bombing or ground fighting and it was used as a mustering base for the British $2^{\text {nd }}$ Battalion Coldstream Guards, who were joined there on 28 March 1944 by 'S' Company Scots Guards. In 1945 he passed from the province of Benevento to that of Caserta.

The historic centre of San Potito Sannitico has ancient origin and taken its actual aspect from spontaneous aggregation of constructions developed over the centuries. 


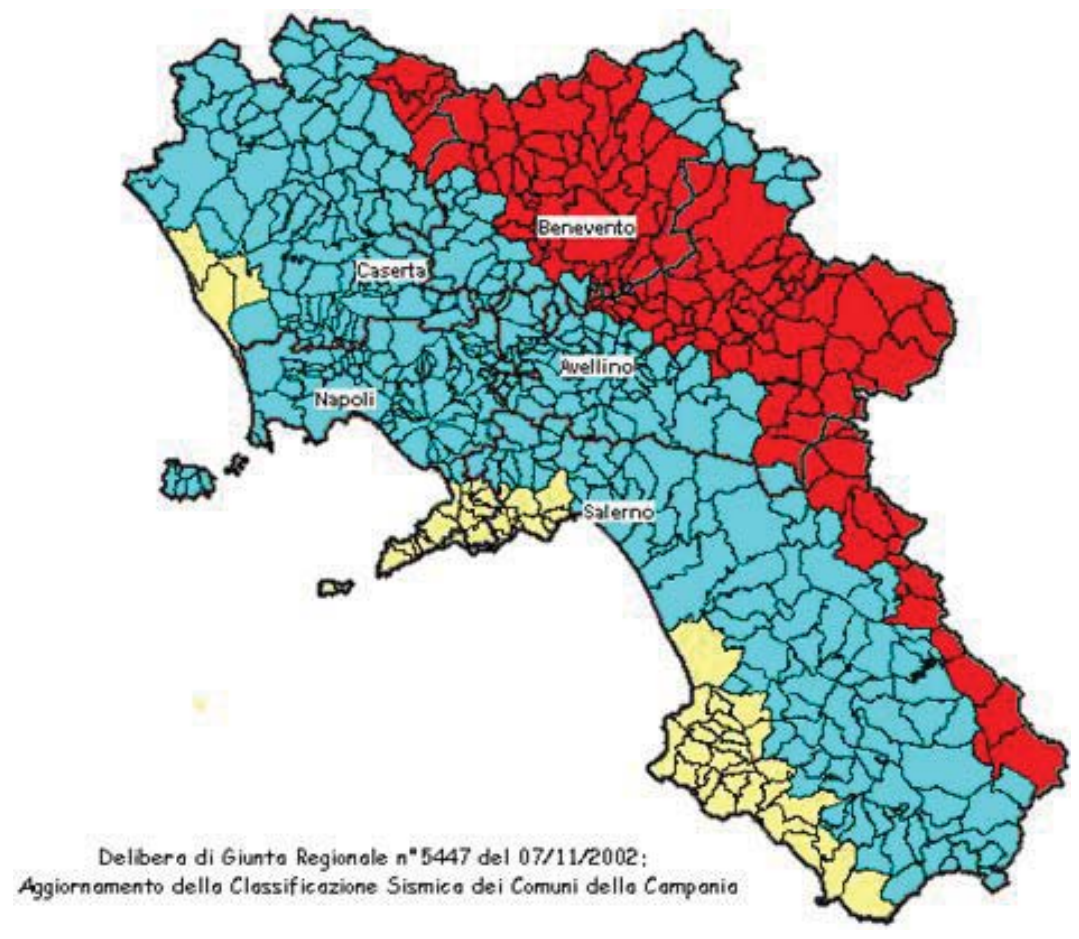

Fig. (7). Different seismicity zones of the Campania region.

The urban structure is composed by a fairly homogeneous small building system developed along a succession of narrow streets leading to open spaces hosting the most important buildings, having facades richly decorated with stuccos, which were erected in the seventeenth and eighteenth Centuries.

The survey carried out showed that the urban centre of the municipality of San Potito Sannitico is characterized by predominantly masonry buildings, whose constructions has followed a natural process of building aggregation, sometimes incongruous, whose stratifications and changes manifest themselves, in many cases, levels of seismic vulnerability not negligible.
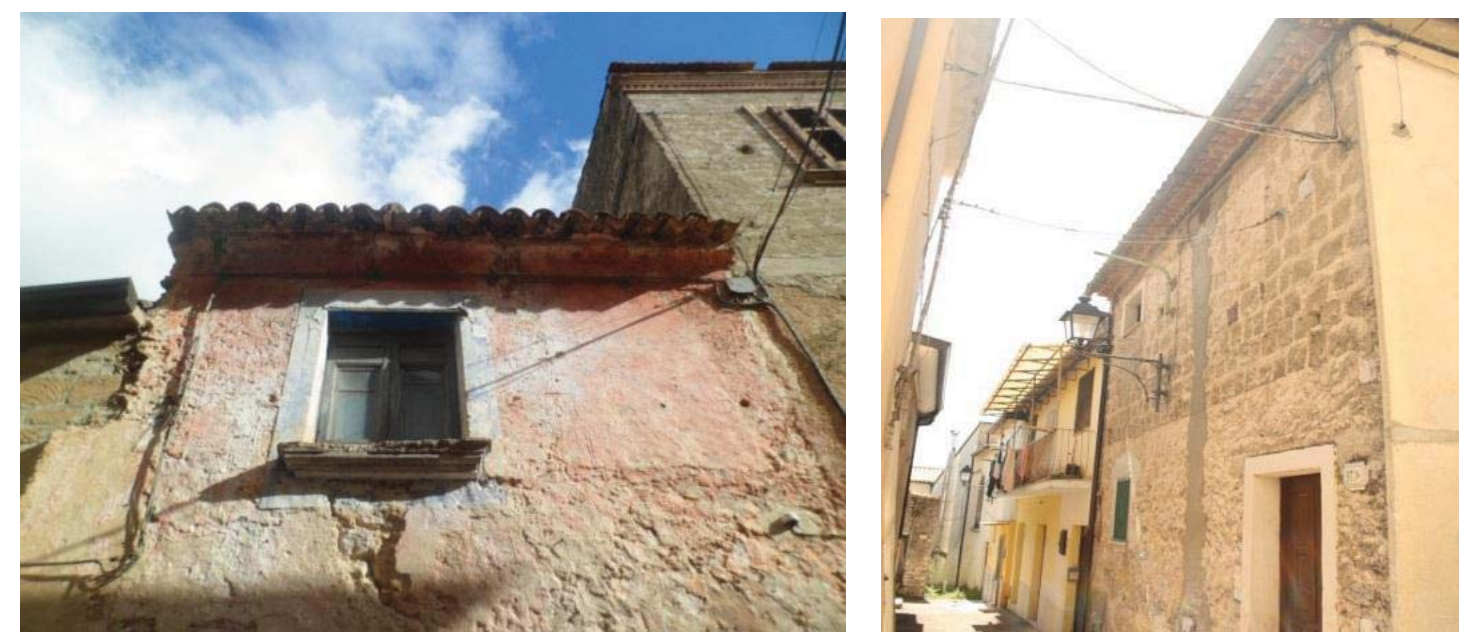

Fig. (8). Inhomogeneity of masonry materials.

The buildings are grouped into aggregates (approximately $95 \%$ of total buildings present in the area), a set of nonhomogeneous buildings, interconnected between them, which can interact each to other under seismic actions. These buildings have multiple factors of vulnerability. Among them, the most recognized factors are related to the inhomogeneity of the load bearing masonry structures, which is accompanied by the coexistence of materials with very different characteristics of stiffness and resistance (Fig. 8). It many cases the presence in the walls of an incongruous 
and brittle binder, which lost over time its characteristics, compromises the static nature of the buildings themselves and, sometimes, of the whole aggregate. Therefore, renovation works to be carried out are planned, they usually leading towards the construction of new structural parts generally not perfectly linked to the existing structures.

The presence of these vulnerability factors increases the possibility of collapse and instability of the historical builtup when subjected to an impacting seismic action. The lack of connections among perimeter walls orthogonal each to other (corners) does not guarantee a global behaviour of the structure. As a negative consequence, in case of earthquake, the activation of the most risky out-of-plane collapse mechanisms (overturning, vertical arch effect, horizontal arch effect, corner overturning), that may invest one or more structural units, can occur [32] (Fig. 9).

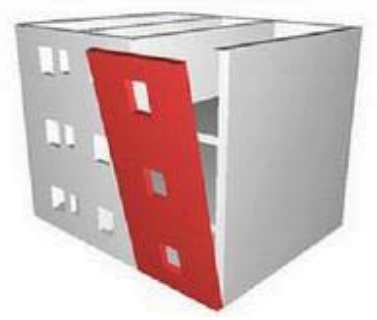

a)

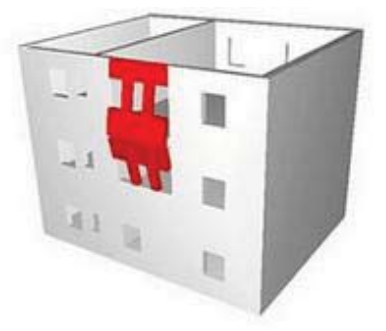

b)

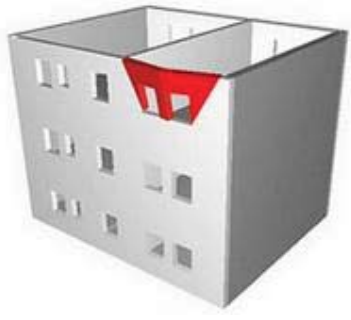

c)

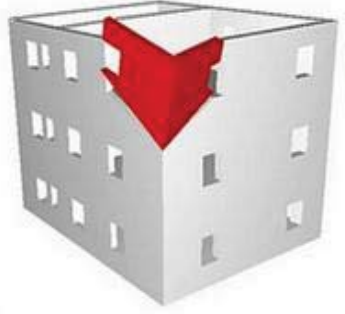

d)

Fig. (9). Main out of plane collapse mechanisms: a) overturning; b) vertical arch effect; $c$ ) horizontal arch effect; $d$ ) corner overturning.

In the historical centre of San Potito Sannitico ten building aggregates composed of 43 Structural Units (S.U.) have been herein examined (Fig. 10). Each aggregate is referred to by a letter [A, B, C, D, E, F, G, H, I, L], while the structural units are referred to by a number $[1 \div 8]$. In order to assess the vulnerability of these aggregates, some surveys have been performed with the purpose to acquire their photographs and drawings.

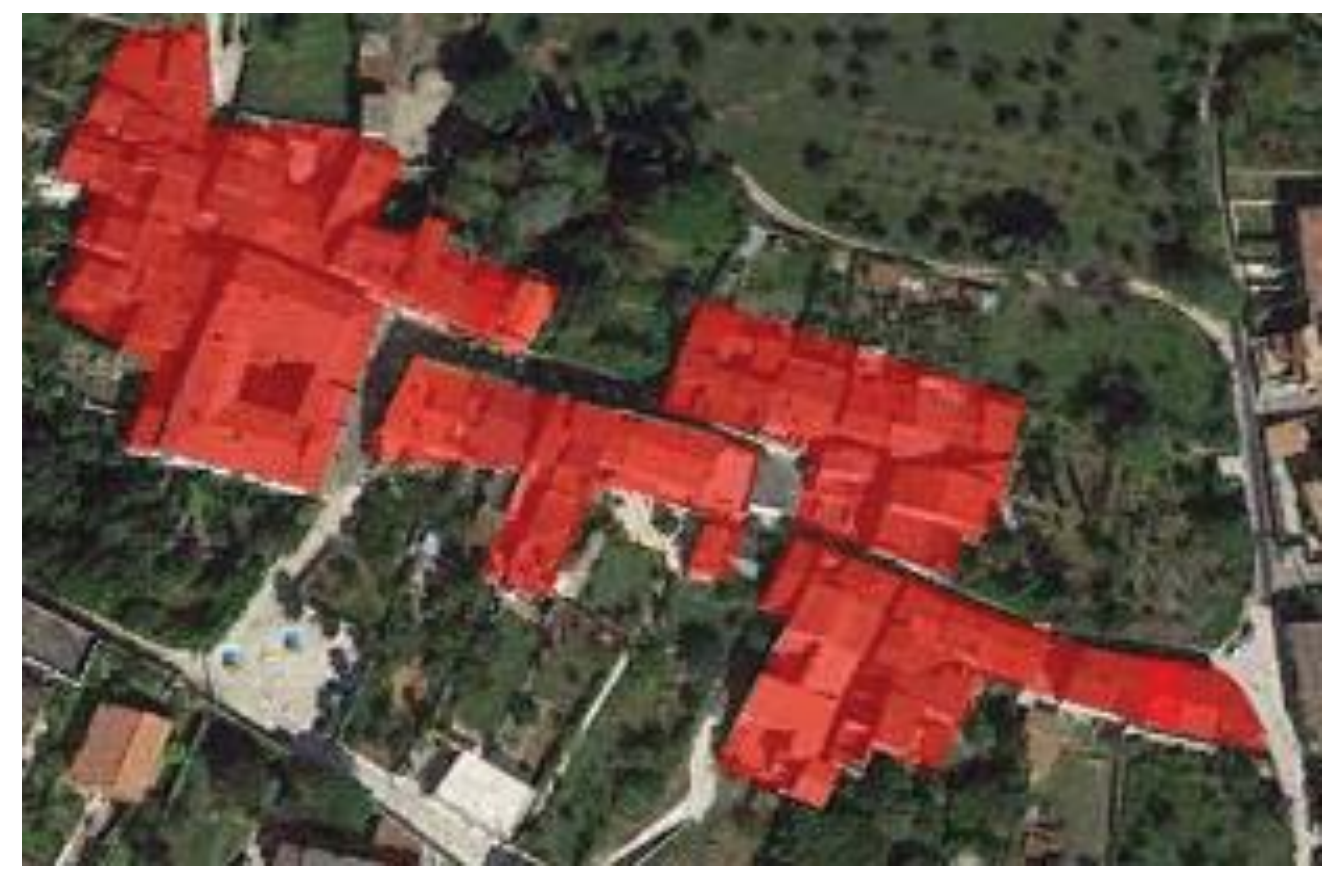

Fig. (10). Bird-eye-view of the historical centre of San Potito Sannitico.

The masonry aggregates under study generally develop in elevation from 2 to 3 stories. The inter-storey height is about 3.00-4.00 $\mathrm{m}$ for the first level and 3.00-3.50 $\mathrm{m}$ for other floors. Horizontal structures are made of either steelhollow tile floors or timber ones. Instead, roofing structures are often composed of double pitch timber beams with clay tile covering. 
Vertical structures are made of tuff or brick masonry squared stones (51\%), masonry roughly squared stones and bricks in bad conditions (35\%) and masonry irregular stones (14\%). Masonry walls usually have constant thickness along the building height, with values between 50 and $70 \mathrm{~cm}$.

In the case under study, the quick methodology has been applied to all the building compounds, but, for the sake of example, only the aggregate $H$ has been examined in detail. It is organised into eight structural units shown in Fig. (11), which are interconnected by means of common walls. They have a material inhomogeneity due to different construction techniques that characterised the town over the years.

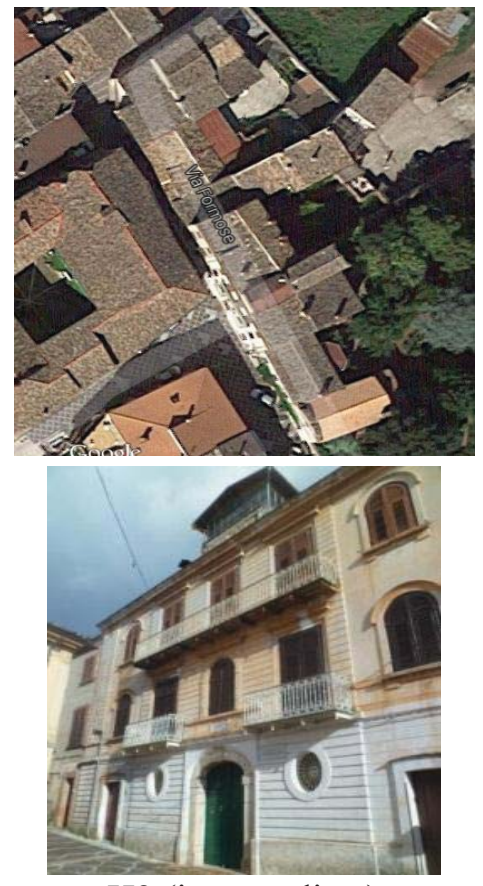

H3 (intermediate)

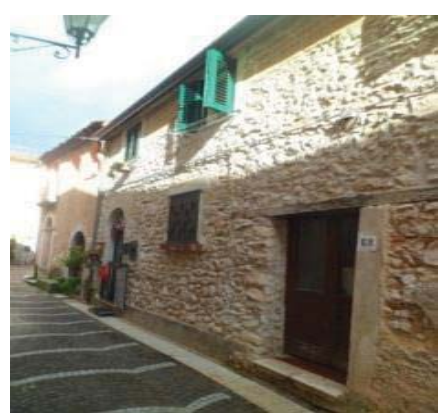

H6 (intermediate)

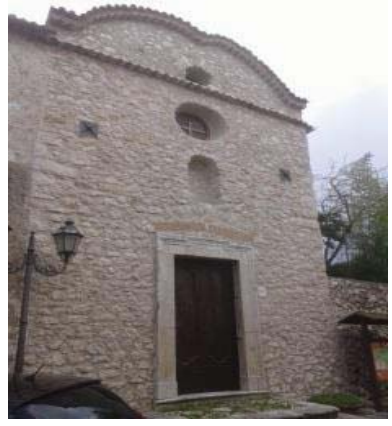

H1 (head)

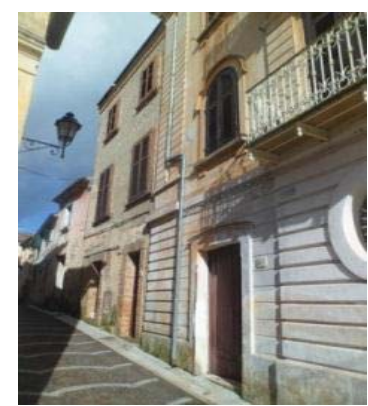

H4 (intermediate)

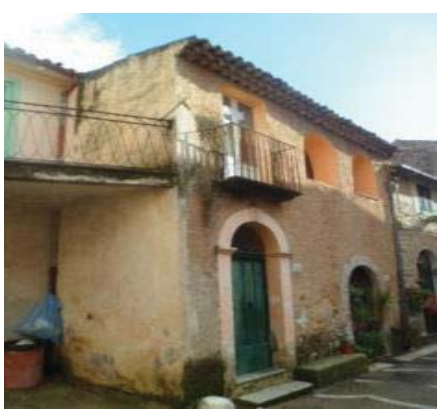

H7 (corner)

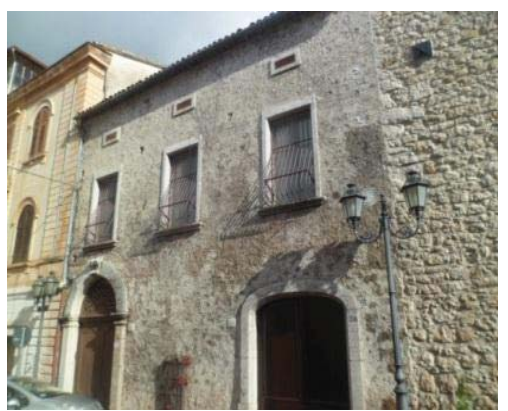

$\mathrm{H} 2$ (intermediate)

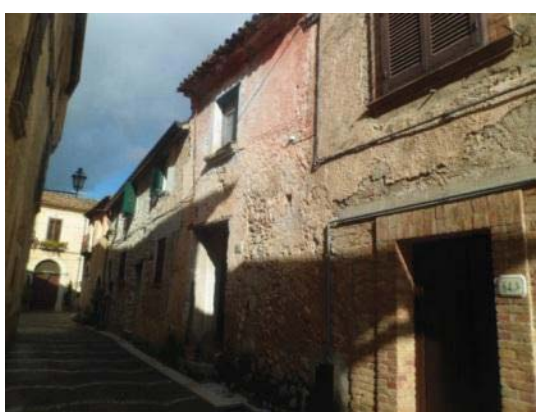

H5 (intermediate)

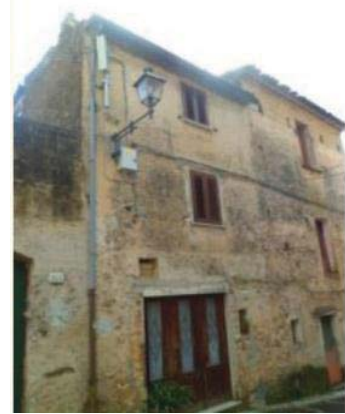

H8 (head)

Fig. (11). Structural Units of the aggregate $H$.

The S.U. have also irregularities in elevation, as well as they show the presence of staggered floors due to the different inter-storey height of S.U. belonging to the same aggregate.

The structural units H1, H3 and H4 are buildings of historical interest, which show a good preservation state. The other structural units composing the aggregate are made of ancient structures with obvious degradation signs. The vertical structures are made of squared stones held together by means of binder with poor mechanical characteristics. The horizontal structures do not guarantee an adequate in-plane stiffness and they often are made up of either timber members or steel ones.

The seismic vulnerability of inspected aggregates has been evaluated before considering the S.U. as isolated constructions, by applying the original vulnerability form with ten parameters [28], and after assessing the influence of 
the interactions with the adjacent S.U., by taking into account the fifteen parameters form also considering the more or less benefits deriving from the aggregate condition [9, 29, 31], also in terms of vibration periods [33]. The latter vulnerability form was developed by some of the Authors starting from damages detected into masonry building compounds after the 2009 L'Aquila earthquake [34, 35]. The vulnerability indices $I_{\mathrm{v}(10)}$ and $I_{\mathrm{v}(15)}$ achieved from the two forms with 10 and 15 parameters, respectively, applied to the selected aggregates, whose plan configurations are depicted in Fig. (12), are shown in Fig. (13).

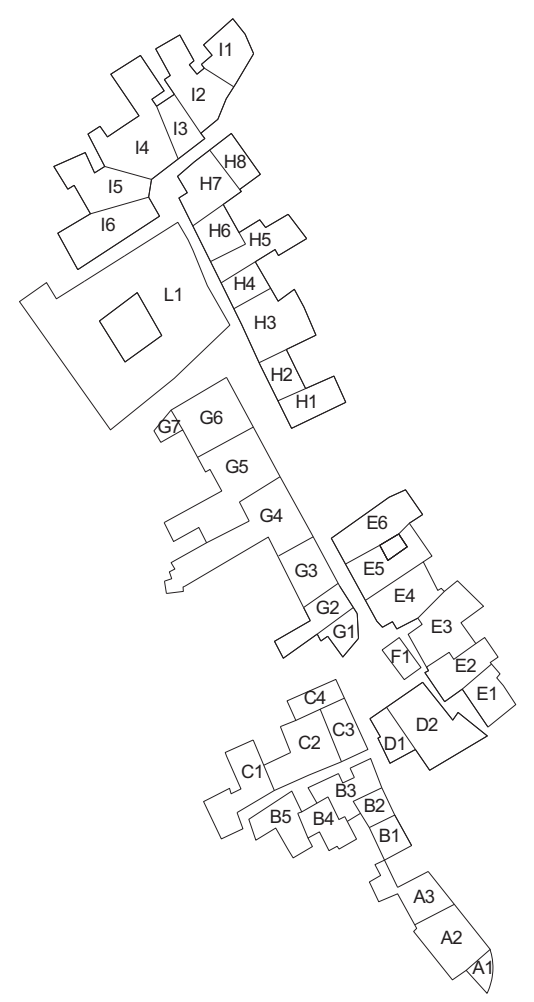

Fig. (12). Plan configuration of examined historical aggregates.

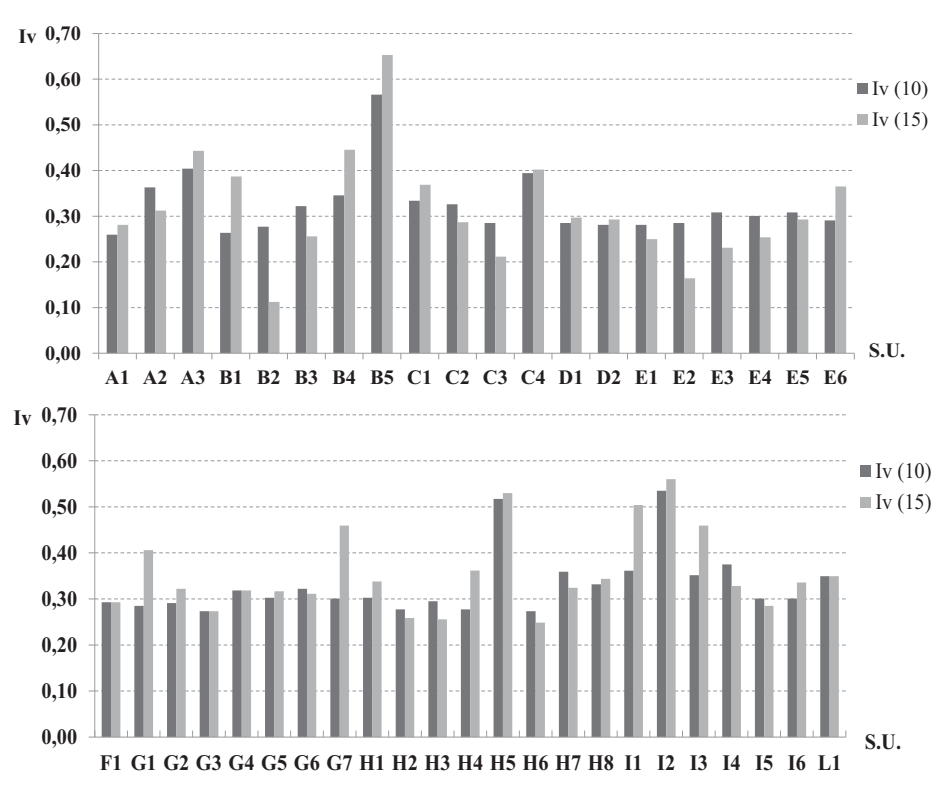

Fig. (13). Vulnerability indices of examined masonry building aggregates.

As it is seen from the histograms above, with respect to the isolated constructions inspected, the seismic 
vulnerability of aggregated S.U., calculated using the form with 15 parameters, increases for head buildings (A1, B5, ..., G1, I1), while the same vulnerability is reduced for buildings that occupy intermediate or corner positions.

This result shows how the interaction with the adjacent buildings has a beneficial effect on the S.U. overall vulnerability, because of the confining effect, offered by contiguous structural units on those landlocked or placed in angle position, able to reduce the propensity at damage. Unlike, the head structural units, that have three free sides, can deform much more under earthquake and, therefore, are subjected to greater damage.

In Fig. (14) the average value of the vulnerability indexes of individual aggregates, calculated by making the mean value of the indexes achieved on single S.U. through the forms with 10 and 15 parameters applied, are shown.

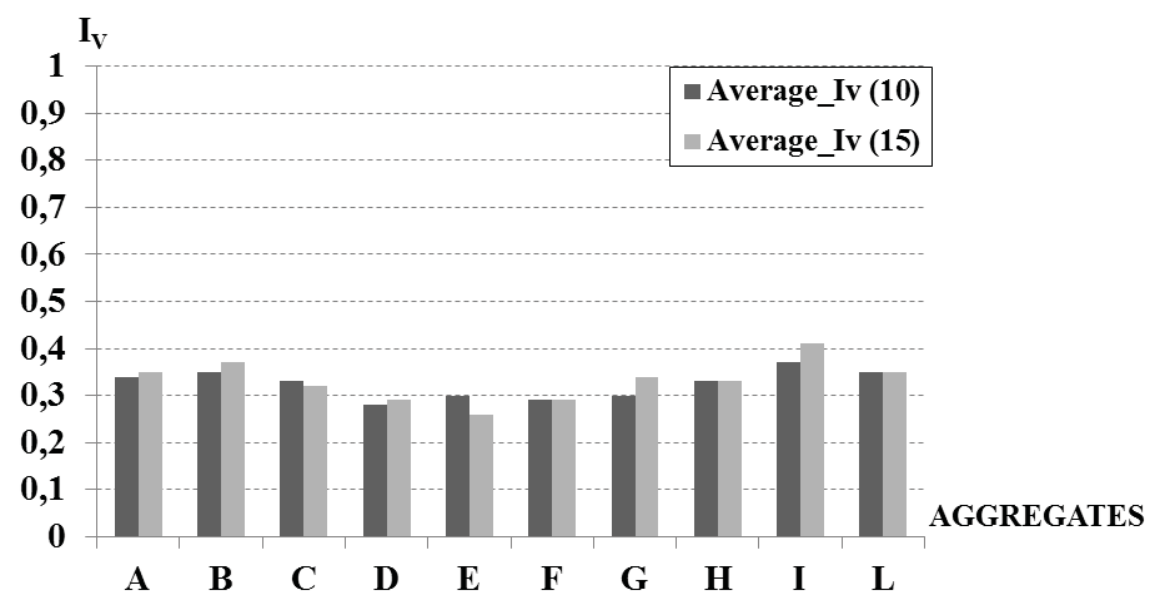

Fig. (14). Average vulnerability index of examined aggregates.

From the analysis of the results is possible to see that the average vulnerability index calculated using only 10 parameters generally underestimates the real aggregate vulnerability, since it does not take into account the mutual interactions among adjacent buildings that, under the global point of view, increase the structural vulnerability.

\section{THE DAMAGE SCENARIO}

The results obtained by the above expeditious analysis provide a relative assessment of the vulnerability, indicating only what is the susceptibility at damage of a building with respect to another one. In order to assess the damages should be suffered by building aggregates under different earthquakes, the methodology proposed in Lagomarsino and Giovinazzi [3] has been used.

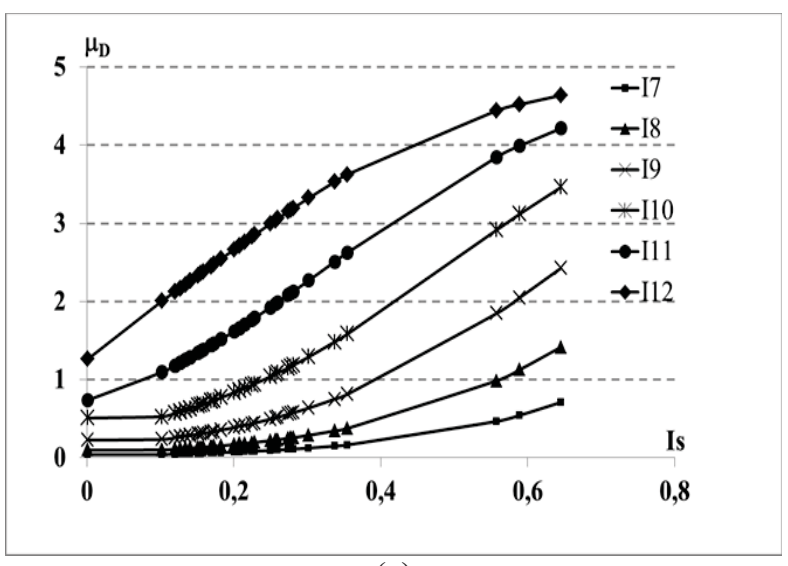

(a)

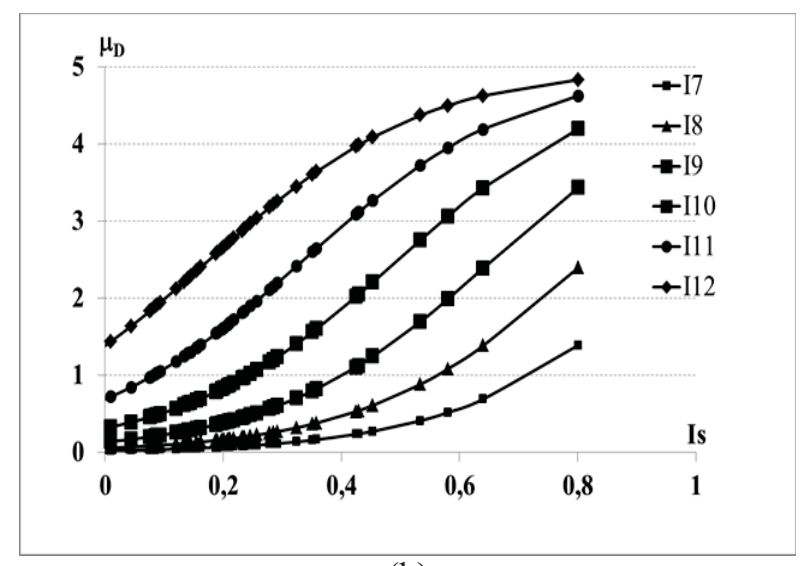

(b)

Fig. (15). Average damage degree vs. vulnerability index for isolated (a) and aggregated (b) S.U.

This method is based on the definition of the average damage degree $\mu_{\mathrm{D}}$, a parameter variable between zero and five, 
where the former and the latter indicate absence of damage and building collapse, respectively. In the case under study, by varying the macro-seismic grade $I_{\mathrm{s}}$ from 7 to 12 , the average damage degrees of S.U. belonging to the inspected masonry building compounds have been assessed starting from the vulnerability indices before calculated through the forms with 10 (Fig. 15a) and 15 (Fig. 15b) parameters.

The curves shown in the mentioned figures, called fragility curves [36], are used to estimate the probability of collapse of buildings when they are subjected to seismic actions. From these results it is noticed that the damage distribution for low vulnerability indexes $(0 \div 0.4)$ provides for both methods the same results. Contrary, for greater vulnerability indexes, the damage distribution is slightly increased when using the 15 parameters form, as it considers the mutual interactions among buildings belonging to the same aggregate. This result is mainly conditioned from head aggregated S.U., which exhibit much more seismic susceptibility at the damaging effect due to the torsional movements experienced under earthquakes.

The damage maps referred to $I_{\mathrm{s}}=12$ for isolated S.U. and aggregated ones are shown in Fig. (16).
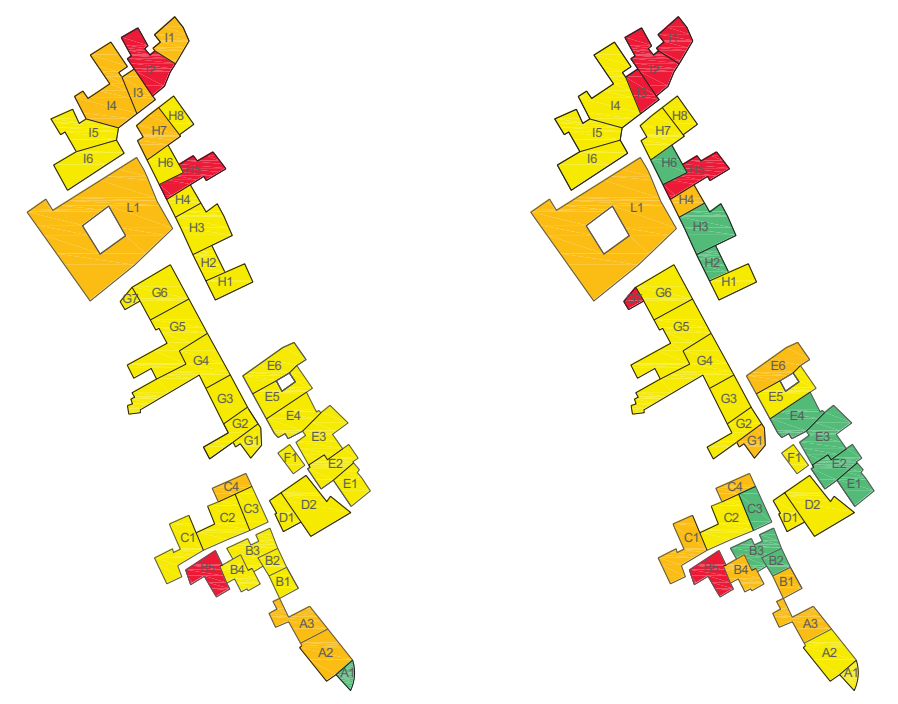

DAMAGE SCALE:

$\square[0 ; 1]$ WITHOUT DAMAGE

$\square[1 ; 2]$ MODERATE DAMAGE

$\square[2 ; 3]$ SERIOUS DAMAGE

$[3 ; 4]$ VERY SERIOUS DAMAGE $\square[4 ; 5]$ COLLAPSE

Fig. (16). Damage maps of isolated (a) and aggregated (b) S.U. $\left(I_{\mathrm{s}}=12\right)$.
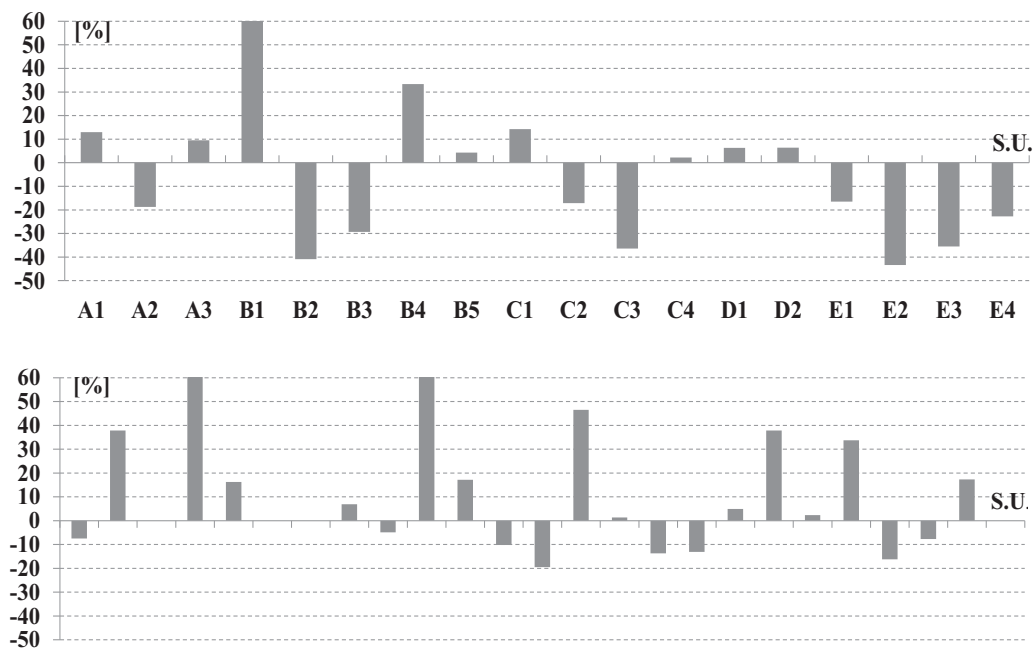

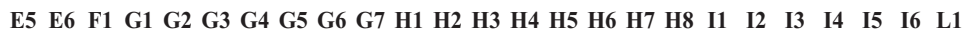

Fig. (17). Damage percentage variation between isolated S.U. and aggregated ones (+: damage increase; -: damage decrease) at a macro-seismic grade $I_{\mathrm{s}}=12$.

In the last figure it is apparent that, when placed into aggregates, some S.U. with intermediate and corner positions 
show a damage reduction, whereas others in the corners have increased damage levels.

In Fig. (17) the percentage differences in terms of damage among S.U. considered as isolated buildings and the same units grouped into aggregates for $I_{\mathrm{s}}=12$ are shown. If average values of these percentage differences are considered, it is achieved that, when inserted within compounds, the damage level is higher for headed buildings (increase of $22.15 \%$ ), whereas it is reduced for intermediate buildings (decrease of 5.85\%) and corner ones (decrease of $18.30 \%$ ). This confirm the beneficial effect of the aggregate condition for intermediate and corner S.U. Contrary, the aggregate detrimental effect is evident for headed S.U., which show higher damage levels due to the torsion effects typical of compounds with elongated plan layouts.

\section{CONCLUSION}

In the paper the seismic vulnerability and damage of an urban sector with ten building aggregates within the historical centre of San Potito Sannitico (district of Caserta) has been presented. First, with reference to a seismic vulnerability analysis, both the basic survey form for isolated constructions and an innovative one for aggregated buildings have been applied to the case study. The analysis results have shown that the aggregate condition reduces the vulnerability of intermediate and corner S.U. and increases the vulnerability of those placed in heading positions. Later on, the damage scenario of inspected aggregates, having seismic vulnerability calculated according to the two applied methods, has been plotted under different grade earthquakes. The percentage differences detected in terms of average damage level between aggregated buildings and isolated ones have shown that, when inserted within compounds, the damage level is higher for headed buildings (increase of $22.15 \%$ ), whereas it is reduced for intermediate buildings (decrease of $5.85 \%$ ) and corner ones (decrease of $18.30 \%$ ). This confirms the beneficial effect of the aggregate condition for intermediate and corner S.U., as well as the detrimental effect evidenced for headed S.U. Moreover, the average value of the vulnerability indexes of individual aggregates, calculated as mean value of those indexes gotten from the forms applied to the inspected S.U., usually underestimates the real aggregate vulnerability when the 10 parameters form is used.

Finally, the fragility curves achieved for S.U. considered as isolated constructions and within compounds provide very similar damage distributions for low vulnerability indexes $(0 \div 0.4)$. Contrary, for greater vulnerability indexes, the damage distribution is slightly increased when using the 15 parameters form, as it considers the mutual interactions among buildings belonging to the same aggregate. This outcome is mainly dictated by head aggregated S.U., which show a seismic susceptibility at damage greater than that of isolated S.U. due to the largest torsional movements experienced under earthquakes.

\section{CONSENT FOR PUBLICATION}

Not applicable.

\section{CONFLICT OF INTEREST}

The authors declare no conflict of interest, financial or otherwise.

\section{ACKNOWLEDGEMENTS}

Declared none.

\section{REFERENCES}

[1] A. Giuffré, and C. Carocci, "Statics and dynamics of historical masonry buildings", Int. Workshop on Structural Restoration of Historical Buildings in Old City Centers, Heraklion, Crete, 1994.

[2] Ministerial Decree of Public Works (M. D.), "New technical codes for constructions (in Italian)", Official Gazette of the Italian Republic n. 29 published on 2008, February 4th, pp. 1-438, 2008.

[3] S. Lagomarsino, and S. Giovinazzi, "Macroseismic and Mechanical Models for the Vulnerability Assessment of Current Buildings", Bull. Earthquake Eng., vol. 4, no. 4, pp. 415-443, 2006. [http://dx.doi.org/10.1007/s10518-006-9024-z]

[4] L. Binda, and A. Saisi, "Research on historic structures in seismic areas in Italy", Prog. Struct. Eng. Mater., vol. 7, no. 2, pp. 71-78, 2005. [http://dx.doi.org/10.1002/pse.194]

[5] Ministerial Circular, "Instructions for the application of the "New technical codes for constructions" - M.D. 14/01/08 (in Italian)", Official Gazette of the Italian Republic n. 47 published on 2009, February 26th, pp. 1-447, 2009. 
[6] D. Benedetti, G. Benzoni, and M.A. Parisi, "Seismic vulnerability and risk evaluation for old urban nuclei", Earthquake Eng. Struct. Dynam., vol. 16 , no. 2, pp. 183-201, 1988. [http://dx.doi.org/10.1002/eqe.4290160203]

[7] M.R. Valluzzi, M. Munari, C. Modena, L. Binda, G. Cardani, and A. Saisi, "Multilevel Approach to the Vulnerability Analysis of Historic Buildings in Seismic Areas - Part 2: Analytical Interpretation of Mechanisms for Vulnerability Analysis and Structural Improvement", Restoration of Buildings and Monuments, vol. 13, no. 6, pp. 427-441, 2007. [http://dx.doi.org/10.1515/rbm-2007-6172]

[8] A. Formisano, F.M. Mazzolani, G. Florio, and R. Landolfo, "A quick methodology for seismic vulnerability assessment of historical masonry aggregates", Proceedings of the Final Conference, 2010 pp. 577-582 Naples, Italy

[9] A. Formisano, F.M. Mazzolani, G. Florio, R. Landolfo, G. De Masi, G. Delli Priscoli, and M. Indirli, "Seismic vulnerability analysis of historical centres: A GIS application in Torre del Greco", Proceedings of the Final Conference, 2010 pp. 583-588 Naples, Italy

[10] A. Formisano, "Seismic behavior and retrofitting of the Poggio Picenze historical centre damaged by the L'Aquila earthquake", In: CivilComp Proceedings, vol. 99. 2012.

[11] V.I. Novelli, D. D’Ayala, N. Makhloufi, D. Benouar, and A. Zekagh, "A procedure for the identification of the seismic vulnerability at territorial scale. Application to the Casbah of Algiers", Bull. Earthquake Eng., vol. 13, no. 1, pp. 177-202, 2014. [http://dx.doi.org/10.1007/s10518-014-9666-1]

[12] R. Maio, R. Vicente, A. Formisano, and H. Varum, "Seismic vulnerability of building aggregates through hybrid and indirect assessment techniques", Bull. Earthquake Eng., vol. 13, no. 10, pp. 2995-3014, 2015. [http://dx.doi.org/10.1007/s10518-015-9747-9]

[13] L.F. Ramos, and P.B. Lourenço, "Modeling and vulnerability of historical city centers in seismic areas: a case study in Lisbon", Eng. Struct., vol. 26 , no. 9, pp. 1295-1310, 2004.

[http://dx.doi.org/10.1016/j.engstruct.2004.04.008]

[14] I. Senaldi, G. Magenes, and A. Penna, "Numerical investigations on the Seismic Response of Masonry Building Aggregates", Adv. Mat. Res., vol. 133-134, pp. 715-720, 2010.

[http://dx.doi.org/10.4028/www.scientific.net/AMR.133-134.715]

[15] L.G. Pujades, A.H. Barbat, R. González-Drigo, J. Avila, and S. Lagomarsino, "Seismic performance of a block of buildings representative of the typical construction in the Eixample district in Barcelona (Spain)", Bull. Earthquake Eng., vol. 10, no. 1, pp. 331-349, 2012. [http://dx.doi.org/10.1007/s10518-010-9207-5]

[16] F. Bucchi, S. Arangio, and F. Bontempi, "Seismic assessment of an historical masonry building using nonlinear static analysis", $14^{\text {th }}$ International Conference on Civil, Structural and Environmental Engineering Computing, CC 2013, vol. 102, 2013 Cagliari, Italy

[17] F. da Porto, M. Munari, A. Prota, and C. Modena, "Analysis and repair of clustered buildings: Case study of a block in the historic city centre of L'Aquila (Central Italy)", Constr. Build. Mater., vol. 38, pp. 1221-1237, 2013. [http://dx.doi.org/10.1016/j.conbuildmat.2012.09.108]

[18] A. Formisano, C. Castaldo, and F.M. Mazzolani, "Non-Linear analysis of masonry building compounds: A comparison of numerical and theoretical results", In: Civil-Comp Proceedings, vol. 102. 2013.

[19] A. Formisano, "Theoretical and Numerical Seismic Analysis of Masonry Building Aggregates: Case Studies in San Pio Delle Camere (L’Aquila, Italy)", J. Earthquake Eng., vol. 21, no. 2, pp. 227-245, 2017.

[http://dx.doi.org/10.1080/13632469.2016.1172376]

[20] F. Galadini, C. Meletti, A. Rebez, Eds., GNDT researches in the seismic hazard field (1996-1999)., CNR-GNDT: Rome, 2000, pp. 1-397. (in Italian)

[21] A.I. Khuri, H.J. Kim, and Y. Um, "Quantile plots of the prediction variance for response surface designs", Comput. Stat. Data Anal., vol. 22, no. 4, pp. 395-407, 1996.

[http://dx.doi.org/10.1016/0167-9473(95)00058-5]

[22] R. Secanell, X. Goula, T. Susagna, J. Fleta, and A. Roca, "Seismic hazard zonation of Catalonia, Spain, integrating random uncertainties", J. Seismol., vol. 8, no. 1, pp. 25-40, 2004. [http://dx.doi.org/10.1023/B:JOSE.0000009516.91044.51]

[23] M. Di Cecca, and S. Grimaz, "The new Friuli Earthquake Damage (Fr.E.D) database", Boll. Geofis. Teor. Appl., vol. 50, pp. 277-287, 2009.

[24] S. Grimaz, "Seismic damage curves of masonry buildings from Probit analysis on the data of the 1976 Friuli earthquake (NE of Italy)", Boll. Geofis. Teor. Appl., vol. 50, pp. 289-304, 2009.

[25] N. Lantada, J. Irizarry, A.H. Barbat, X. Goula, A. Roca, T. Susagna, and L.G. Pujades, "Seismic hazard and risk scenarios for Barcelona, Spain, using the Risk-UE vulnerability index method", Bull. Earthquake Eng., vol. 8, no. 2, pp. 201-229, 2010. [http://dx.doi.org/10.1007/s10518-009-9148-z]

[26] M.C. Marulanda, M.L. Carreño, O.D. Cardona, M.G. Ordaz, and A.H. Barbat, "Probabilistic earthquake risk assessment using CAPRA: application to the city of Barcelona, Spain", Nat. Hazards, vol. 69, no. 1, pp. 59-84, 2013 [http://dx.doi.org/10.1007/s11069-013-0685-z]

[27] I. Iervolino, G. Fabbrocino, and G. Manfredi, "Fragility of Standard Industrial Structures by a Response Surface Based Method", J. 
Earthquake Eng., vol. 8, pp. 927-946, 2004.

[http://dx.doi.org/10.1080/13632460409350515]

[28] D. Benedetti, and V. Petrini, "On the seismic vulnerability of masonry buildings: an evaluation method", L'industria delle Costruzioni, vol. 149, pp. 66-74, 1984.

[29] A. Formisano, G. Florio, R. Landolfo, and F.M. Mazzolani, "Numerical calibration of a simplified procedure for the seismic behaviour assessment of masonry building aggregates", Proceedings of the $13^{\text {th }}$ International Conference on Civil, Structural and Environmental Engineering Computing, 2011 Chania, Crete.

[30] S. Lagomarsino, A. Penna, A. Galasco, and S. Cattari, "TREMURI program: an equivalent frame model for the nonlinear seismic analysis of masonry buildings", Eng. Struct., vol. 56, pp. 1787-1799, 2013. [http://dx.doi.org/10.1016/j.engstruct.2013.08.002]

[31] A. Formisano, G. Florio, R. Landolfo, and F.M. Mazzolani, "Numerical calibration of an easy method for seismic behaviour assessment on large scale of masonry building aggregates", Adv. Eng. Softw., vol. 80, pp. 116-138, 2015. [http://dx.doi.org/10.1016/j.advengsoft.2014.09.013]

[32] A. Formisano, N. Chieffo, B. Milo, and F. Fabbrocino, "The influence of Local Mechanisms on Large Scale Seismic Vulnerability Estimation of Masonry Building Aggregates", Int. Conference of Computational Methods in Sciences and Engineering 2016 (ICCMSE 2016), AIP Conf. Proc. 1790, art. no. 130010, 2016 pp. 1-4. [http://dx.doi.org/10.1063/1.4968728]

[33] A. Formisano, N. Chieffo, D. Monaco, and F. Fabbrocino, "On the Influence of the Aggregate Condition on the Vibration Period of Masonry Buildings: a Case Study in the District of Naples", AIP Conf. Proc, 2016 pp. 1-4. [http://dx.doi.org/10.1063/1.4968723]

[34] A. Formisano, P. Di Feo, and M. R. Grippa, "L'Aquila earthquake: A survey in the historical centre of Castelvecchio Subequo", In: COST ACTION C26: Urban Habitat Constructions under Catastrophic Events, Proceedings of the Final Conference, Naples, Italy, 2010, pp. 371-376.

[35] M. Indirli, L.A. Kouris, A. Formisano, R.P. Borg, and F.M. Mazzolani, "Seismic damage assessment of unreinforced masonry structures after the Abruzzo 2009 earthquake: The case study of the historical centers of L'Aquila and Castelvecchio Subequo", Int. J. Archit. Herit., vol. 7, no. 5, pp. 536-578, 2013. [http://dx.doi.org/10.1080/15583058.2011.654050]

[36] M. Rota, A. Penna, and G. Magenes, "A methodology for deriving analytical fragility curves for masonry buildings based on stochastic nonlinear analyses", Eng. Struct., vol. 32, pp. 1312-1323, 2010. [http://dx.doi.org/10.1016/j.engstruct.2010.01.009]

(C) 2017 Formisano et al.

This is an open access article distributed under the terms of the Creative Commons Attribution 4.0 International Public License (CC-BY 4.0), a copy of which is available at: https://creativecommons.org/licenses/by/4.0/legalcode. This license permits unrestricted use, distribution, and reproduction in any medium, provided the original author and source are credited. 